\title{
Research on embedded counselling: An emerging topic of potential importance for the future of counselling psychology
}

John McLeod Julia McLeod

This is an Accepted Manuscript of an article published by Taylor \& Francis in Counselling Psychology Quarterly on 4th August 2014, available online:

http://www.tandfonline.com/10.1080/09515070.2014.942774 
Pre-publication version of: McLeod, J., \& McLeod, J. (2015). Research on embedded counselling: An emerging topic of potential importance for the future of counselling psychology. Counselling Psychology Quarterly, 28(1), 27-43. https://doi.org/10.1080/09515070.2014.942774

Research on embedded counselling: an emerging topic of potential importance for the future of counselling psychology

\begin{abstract}
A significant proportion of the counselling that people receive takes place within informal, situated encounters between service users and practitioners in fields such as nursing, medicine, teaching and social work. However, almost all of the research that has been carried out into the process and outcomes of counselling consists of studies of formal, contracted counselling and psychotherapy based in therapy clinics and offices. The competent and effective delivery of counselling that is embedded in a primary professional role, such as that of nurse, teacher or social worker, presents considerable challenges for practitioners. Research evidence around the process and outcomes of embedded counselling represents a valuable resource that has the potential to enhance the quality of counselling conversations enacted by practitioners in health, education, social work and other professions. An overview is provided of different types of research that has been carried out into informal and embedded counselling, and of the main themes that have emerged from these studies. Suggestions are made for the further development of this field.
\end{abstract}

Keywords: counselling skills; embedded counselling; organisational context; outcome; prevention; process; situated interventions; training. 
In 1945, Virgina Axline and Carl Rogers published an account of the counselling role undertaken by a teacher, over a period of several months, in response to the emotional and social needs of a disabled six-year-old boy who was a member of a class of 36 children for whom she was responsible (Axline \& Rogers, 1945). This descriptive case study illustrated the ways in which this teacher was able to make use of counselling skills, behavioural interventions and consultation with other professionals, to play a key role in the recovery of a seriously troubled young person, mainly through a series of brief, fifteen-minute listening conversations. It is hard to find other, more recent, case examples of this kind of work.

In general, the field of counselling and counselling psychology has moved in the direction of becoming a discrete area of specialised professional activity, in which psychological assistance is provided by therapists in offices, rather than teachers in classrooms. Nevertheless, alongside the development and expansion of counselling and other psychotherapeutic interventions as stand-alone professional activities, individuals with problems in living continued to turn to trusted members of their community, such as nurses, teachers and clergy, for informal emotional support (Anderson \& Brownlie, 2011; Barker et al., 1990).

In an attempt to acknowledge the distinctive characteristics of counselling that takes place outside the therapy room, and is provided by members of other professions, Høigaarda and Mathisen (2008) have developed a model of informal, situated counselling, and McLeod and McLeod (2011) have proposed a framework for training and research in embedded counselling. Along similar lines, Branch and Malik (1993) described the ways in which skilled physicans are able to make use of windows of opportunity within on-going clinical consultations, to enable patients to express and work through emotional issues. 
A substantial body of research has been generated on taxonomies of counselling skills, the impact of the implementation of certain skills (e.g., empathic reflection, challenging, using open questions) on the counselling process, and the effectiveness of training in counselling skills. This work mainly consists of studies of skills development in students in the early stages of training to become counsellors or counselling psychologists. Valuable reviews of this literature can be found in Hill (2001) and Hill and Lent (2006). However, although it is clear that nurses, teachers and other practitioners make use of counselling skills, there has been limited research focus on the ways in which these skills are implemented or adapted in specific settings such as a busy hospital ward or classroom. The aim of the present paper is to examine the types of research evidence that exist in respect of the application of counselling skills in informal and situated, or embedded settings, and to discuss the potential contribution that might be made by researchers within the fields of counselling, counselling psychology and psychotherapy, in the further development of this area of knowledge.

We explore the scope and extent of embedded counselling, then go on to examine the kind of research that has been carried out in relation to a series of topics of practical relevance:. the impact of embedded counselling on health and well-being; the process and outcome of training in embedded counselling skills; practitioner perspectives on the experience of using counselling skills; issues associated with the challenge of responding to expression of emotion; the experience of recipients of embedded counselling; the qualities of helpful and unhelpful embedded counselling conversations; , the organizational context of embedded counselling. The paper concludes by considering emerging themes, areas for further research, and implications for counselling psychology. 
We make no claim that the account of research into embedded counselling offered within the present paper represents a comprehensive review of the existing literature in this area of practice. The studies that have been carried out have used a wide range of methodologies, and are located within a variety of disciplinary and occupational traditions, such as nursing, education and social work, as well as psychology. It would only be possible to do justice to the totality of this material by carrying out a meta-narrative review along the lines of Greenhalgh et al. (2005) - a resource-intensive undertaking that would require the efforts of an interdisciplinary team. Instead, the intention is to provide an appreciation of the scope of research into embedded counselling. Because of space limitations, rather than seeking to provide a detailed account of the methods and findings of all relevant studies, a set of exemplar research studies has been selected to provide an introduction to some of the possibilities that exist in relation to systematic inquiry into the process and outcomes of embedded counselling, and the potential value of different research methodologies.

\section{Research on Embedded Counselling: Key Themes and Topics}

We have organized the following sections around questions that are likely to be of interest to counselling psychology practitioners, trainers and researchers.

Identifying the scope and extent of embedded counselling 
An important questions within this field relates to the extent to which situated and embedded counselling is practised. Survey methods have been used to explore the extent to which the public regard members of professions such as medicine and the clergy as source of emotional support (Anderson \& Brownlie, 2011; Barker et al., 1990; Kane, 2010), and the kinds of embedded counselling issues dealt with by such practitioners (O’Kane \& Millar, 2001). These studies have shown that a significant proportion of individuals regard such practitioners as valued sources of support for psychological problems, and that members of such professions tend to deal with a wide range of emotional issues, such as relationship problems, feelings of anxiety and panic, inability to make decision, and lack of confidence. Surveys conducted by Page and Jacobs (2011) and Tatar (2009) found that employees within human service organisations preferred to talk to colleagues about stress issues, rather than consult a professional therapist.

\section{Client outcomes: the impact of embedded counselling on health and well-being}

A further key question in relation to the use of counselling skills by nurses, social workers, teachers and other practitioners, concerns the effectiveness of these interventions. For example, it may be that practitioners do not have sufficient knowledge and training to deal effectively with counselling situations with which they are faced. Several studies have examined the effect of embedded counselling on the health, well-being and other outcomes in clients and service users. For example, Turner et al. (2010) conducted a study in which women with symptoms of depression received "listening visits" from health visitors who had been trained in counselling skills. The women in this study reported that these visits had been helpful for them, but about two-thirds of them believed that the number of visits had not been sufficient to allow them to deal fully with their problems. In other research on the 
effectiveness of "listening visits," women were randomly assigned either to treatment as usual (routine health visitor and GP involvement with no specific focus on emotional issues), or to a listening visit condition. Using this kind of randomised trial methodology, it was found that listening visits were more effective than usual GP and health visitor care in reducing postnatal depression (Holden, Sagovsky \& Cox 1989; Morrell et al., 2009).

Downing et al. (2006) used a randomised trial methodology to examine the effectiveness of counselling skills in work with bereaved adults with intellectual disabilities. In this investigation, clients who had experienced a recent bereavement were randomly allocated either to receive specialist bereavement counselling, or to be helped by carers who had undergone some counselling skills training. The findings of this study were that the specialist counselling was more effective than embedded counselling, probably because the carers delivering embedded counselling lacked confidence in their ability to deal with the issues being presented by clients.

Gao, Chan and Sun (2012) conducted a randomised trial in which, three months following the birth of their first child, mothers received either a standard education programme, organised around the provision of information about childbirth and baby care, or an adapted programme which included elements of nurse-led embedded counselling. At follow-up, postnatal depression was lower, and well-being was higher, in those women who had received the therapeutically-oriented intervention.

These studies demonstrate that it is possible to conduct controlled outcome studies of embedded counselling in naturalistic settings, and that the results of such research have the potential to inform policy and practice around the amount of counselling that is required, the 
level of training that is necessary, and situations in which specialist services may be more appropriate than embedded counselling that is integrated into existing care. It seems clear that further possibilities exist around the use of practice-based approaches to outcome research in this area, for example through administration of brief outcome scales within routine practice, in order to supplement knowledge from controlled studies or to collect outcome data in settings in which controlled studies are not feasible.

\section{The process and outcome of training in embedded counselling skills}

The adequacy of training in embedded and situated counselling represents a significant issue for practitioners who are being called upon to use counselling skills in high-pressure frontline situations, and for counselling psychologists responsible for the design and delivery of training programmes. Several studies have evaluated the effectiveness of counselling skills training for practitioners in a range of professional groups . In some studies, self-report questionnaires have been administered pre and post-training to assess the participant estimates of her/his own self-efficacy in the use of counselling skills. For example, Lent, Hill and Hoffman (2003) devised the Counsellor Activity Self-Efficacy Scale (CASES), which consists of three sections: helping skills (18 items); session management (17 items); responding to counselling challenges (24 items). The response format used for most items invited participants to "indicate how confident you are in your ability to use each of the following helping skills effectively, over the next week in your work with clients" using a 10 point scale from 0 (no confidence) to 9 (complete confidence). Similar scales have been developed by Kuntze, van der Molen and Born (2007), Hill and Kellems (2002), Larsen (1992), Linden, Stone and Shertzer (1965) and several other researchers. It is also possible to evaluate the perceived effectiveness of training user ultra-brief questionnaires. For 
example, Connolly et al. (2010) developed a questionnaire with a 3-item scale (each item rated 0-10): How competent do you feel in talking to people about their emotional troubles? How confident do you feel in talking to people about their emotional troubles? How willing are you to talk to people about their emotional troubles? This measure was used to evaluate the effectiveness of training workshops for health and social care professionals, and recorded significant shift in the direction of willingness to engage with the emotional concerns of patients. In one particularly innovative study, Quirk et al. (2008) asked a group of patients to devise their own questionnaire to evaluate the quality of the counselling skills exhibited by their physicians.

The advantage of self-report instruments is that they can readily be completed by trainees, and allow a straightforward and cost-effective means of assessing training outcomes. However, these scales have the disadvantage of only evaluating how confident or competent participants perceive themselves to be. Although there is clearly some association between self-perception of competence, and actual performance of counselling skills in real-life situations with clients (see, for example, McLeod \& Rodgers, 2008; Stahl \& Hill, 2008), there is an obvious need to be able to supplement self-report data with findings from studies that use observational data.

A valuable means of collecting direct evidence of practitioner competence in the use of counselling skills, is to analyse audio or video recordings of their interactions with service users in real-life settings, Studies by Adams-Skinner et al. (2009) and Bonvicini et al. (2009) used rating scales to assess the level of counselling skill exhibited in audio-recorded segments of nurses' interactions with clients. Glowa et al (2002) directly assessed the effectiveness of physician counselling skills by sending simulated patients into a hospital 
clinic. Ratings made by simulated patients provided evidence of physician skills within a standardised, but real-life situation. In addition, the knowledge that a simulated patient visit might occur, encouraged trainees to maintain a high level of skill. A systematic review of research evaluations of the effectiveness of training in therapeutic communication, in nursing aides working in institutional settings, carried out by Levy-Storms (2008), provides a valuable discussion of methodological issues associated with this type of research, such as difficulties in sampling relevant observational data, use of long-term follow-up to determine sustainability of skills learning, and reducing practitioner and patient attrition from studies. .

A further area of research into counselling skills training consists of retrospective interviews with experienced practitioners concerning their views regarding the value of training they have received as part of their professional education. For example, O'Kane and Millar (2002) and Leavey, Loewenthal and King (2007) found that clergy believed that their initial counselling skills training had not adequately prepared them to deal with situations that they later encountered in their pastoral roles. Nerdrum and Ronnestad (2002) carried out qualitative interviews with health and social care professionals participating in an intensive training programme intended to enhance their capacity to respond empathically to their clients. The findings of this study are particularly interesting in the extent to which they demonstrate that these practitioners were personally challenged by what they encountered during the training, particularly in respect of changing long-established attitudes and ways of relating. Other research has investigated the content and design of training programmes . For example, Blanch-Hartigan $(2011,2012)$ found that a 30-minute training input could have a positive impact on the micro-skill of responsiveness to emotion cues. Childers (2012) 
reported that a 12-hour programme had a similar positive effect on empathic listening skills in medical residents.

In conclusion, a range of methodological strategies has been developed to explore different aspects of both the process of counselling skills training for healthcare and other practitioners, and the capacity of practitioners to use such skills. An important issue, highlighted by Levy-Storms (2008) but not sufficiently addressed in this body of research as a whole, concerns to the role of on-going mentoring and supervision in the post-training period, as a means of consolidating what has been learned in training.

\section{Practitioner perspectives on the experience of using counselling skills}

A number of studies have invited practitioners to describe their experience of applying counselling skills in their work with service users. Boyle, Kernohan and Rush (2009) interviewed health and social care practitioners around the challenges that they experienced in using counselling skills with difficult clients (patients with histories of violence and mental health problems), and found that an central theme for these practitioners centred on the difficulty of maintaining control of their emotions. Kind, Everett and Ottolini (2009) analysed reflective essays written by medical students undergoing training in empathic skills and identified that a key issue for these students was that of having enough time to use skills in interactions with patients. Incidentally, Kind et al. (2009) also found that the experience of writing these reflective pieces made a positive contribution to student learning.

Several studies have highlighted the ways in which practitioners of embedded counselling develop ways of working that reflect the specific organisational contexts and client groups with which they are involved. In interviews with physicians and nurses about 
the counselling strategies they used in conversations with patients around preventive sexual health consultations, Henderson et al. (2011) found that these healthcare workers had evolved a combination of "parental" authority, empathic connection and innovative problem-solving, as a means of addressing the specific needs of their patient group. Other studies have also found that practitioners of embedded counselling have integrated existing counselling theories and approaches into idiosyncratic "situated working models" (see, for example, Abildsnes et al., 2012; Degner et al., 2007; Easton \& van Laar, 1995; Flesaker \& Larsen, 2012; Porr et al., 2012). Several studies have explored the experiences of clergy in relation to their counselling role (Leavey, Loewenthal, \& King, 2007; Lount \& Hargie, 1997; O’Kane \& Millar, 2002), and described a process of practitioner development that starts with a high level of willingness to adopt a counselling role, combined with a sense of being underprepared for what is being asked from them, leading to selectivity about the types of issues that they are willing to consider and the adoption of a largely cognitive-problem solving approach as a means of self-protection. Engebretson (2000) published a single case analysis of a powerful episode of empathic presence on the part of a nurse accompanying a female patient through the loss of a child. This case study provides evidence of the intensity of emotional connection that is possible in embedded counselling situations.

These studies offer valuable insights into the ways in which counselling skills and models may need to be adapted to meet the needs of specific groups of clients. These studies also offer a basis for beginning to understand some of the specific training and supervision requirements of practitioners offering embedded counselling within different occupational and organisational settings. 
One of the recurring themes within the embedded counselling literature concerns the central role of emotion in this area of work. Clients, patients and service users want to talk about how they feel, and one of the challenges for practitioners is to know when and how to respond to emotional communication. An important organising concept within this area has been the notion of "empathic opportunities." How do practitioners identify empathic opportunities presented by clients, in the form of expressions of emotion, and then how do they respond to these openings? Jansen et al. (2010) analysed audio recordings of nursepatient interactions to examine the extent to which practitioners responded to emotional cues from patients, and the impact on the patient of the kind of response that was offered. In this study, they found that when a nurse acknowledged the emotional expression of the patient, it was more likely that the patient would later recall the content of their discussion. However, when the nurse distanced himself or herself from the patient's emotion, by not acknowledging it, the patient was less likely to recall what happened in the consultation.

Adams et al. (2012) used three categories to analyse physician responses to patient expressions of negative emotion: "away," "toward," and "neutral." "Toward" and "neutral" responses were associated with patient exploration of personal concerns, with "toward" responses also linked to positive patient ratings of the doctor-patient relationship, and higher rates of agreement around eventual treatment plans. Research on empathic opportunities and emotional responsiveness has explored these processes in relation to different groups of healthcare workers (Bylund \& Makoul, 2002; Eide et al., 2004; Kennifer et al., 2009; Sheldon et al., 2009). A number of different rating scales and questionnaires to assess emotional responsiveness and empathic responding has been developed in the course of this programme of research (see, for example, Mercer et al. 2004, 2005). Issues arising from the 
use of these instruments have been reviewed by Stone et al. (2012), who point out that patients may present emotion cues in different ways, and that emotion episodes can vary a great deal in terms of length and intensity. These factors introduce complexity and ambiguity to the task of rating emotion events in real-life health-care environments.

An alternative framework for exploring the emotional dimension of embedded counselling is the concept of "emotional labour" (Hochshchild, 1983), which refers to multiple ways in which workers within certain occupations are required to suppress their own feelings, respond to the emotional needs of others, and display some emotions and not others. These functions represent a significant load on employees, and can lead to stress and health problems. Using an emotional labour scale, Kinman, McFall and Rodriguez (2011), found that the counselling role of clergy was associated with a high degree of emotional labout, but that most respondents believed that they had developed effective strategies for dealing with this aspect of their work.

The issue of how embedded counsellors respond to expressions of emotion in clients and service users, represents substantial possibilities for further research, and the development of training and practice. Within the field of healthcare research, several groups of researchers have constructed valid and reliable instruments for investigating empathic opportunities and practitioner responsiveness to patient emotional expressiveness. To date, these methodologies have not been applied in other domains of embedded counselling such as teaching or social work. The somewhat broader concept of emotional labour, which refers to the accumulative impact on practitioners of responding to empathic opportunities (as well as other forms of "emotion work") has been explored only to a minimal extent.

\section{The experience of recipients of embedded counselling}


An understanding of the experience of recipients of embedded counselling involves an appreciation of the factors that influence the decisions of those who need help in respect of whether to approach a counsellor or psychotherapist, or to seek support from a practitioner of embedded counselling. There exists an extensive research literature around the help-seeking process, some of which is relevant to the field of embedded counselling. Tatar (2009) analysed data from a questionnaire study of teachers, regarding their decision-making around the value of different sources of help for different sources of stress within their professional lives. The teachers in this study reported that, in most circumstances, they preferred to consult with teacher-colleagues rather than with the counsellors who worked in their schools. Using qualitative interviews, Grayson, Miller and Clarke (1998) explored the process of help-seeking in university students, and found that most students preferred to talk to a tutor with whom they were familiar, rather than a university counsellor. Ungar et al. (2009) interviewed survivors of sexual abuse about the challenges that they had overcome in eventually finding someone who would take their problems seriously. All three of these studies showed that the initial source of help, for most individuals, was someone they already knew and trusted, such as a teacher, rather than a professional therapist

Several studies have explored the experiences of clients in relation to the use of counselling skills by practitioners, employing a variety of methodological approaches. Eyrich-Garg (2008) used focus group interviews with adolescent young women in an emergency accommodation shelter in a city in the USA, to inquire about their advice for staff offering them counselling relationships. Based on their experience as recipients of counselling skills, these young women were clear about what they wanted counsellors to do: 
"treat me like I'm on your level," "tell me a little about yourself," "ask my permission to take notes," "pay attention to what I'm saying," "tell me what you're doing," and "don't call me names." Janssen and MacLeod (2010) interviewed people dying of cancer, about their perceptions of the caring attitudes of the physicians who treated them. They reported that effective care occurred when the physician attempted to seek "common ground with the patient as a fellow human being," and that such experiences tended to have a positive impact on their health and well-being.

Bender et al. (2011) carried out a participant observation study, over several months, of relationships between nurses providing home care for patients diagnosed with tuberculosis (TB), a highly infectious disease whose treatment involved severe lifestyle restrictions that often resulted in patient hostility and frustration. This investigation is notable for its sensitive and detailed portrayal of the gradual development of trust, leading eventually to a willingness on the part of patients to discuss important personal issues. Maiter, Palmer and Manji (2006) interviewed parents who had an involvement with social work services around child protection issues, about the quality of their relationships with their social workers. This is a particularly interesting study because many of these clients were engaged in tense and adversarial relationships with social work staff, around custody and access to their children. Nevertheless, even in this context, clients reported that they valued social workers who were caring genuine, empathic, good listeners who offered exceptional help, and resented it when staff were judgmental, insincere, cold and uncaring, poor listeners, or critical. These parents believed that the quality of their relationship with their social workers had a capacity to have a beneficial effect on the outcomes of a social work intervention, by allowing them to keep 
communication channels open even when they disagreed with what the social worker wanted to do.

Similar research studies have addressed preferences for helping style of physicians and nurses in women who reported depression around the time of the birth of a child (Hearnshaw et al., 2011), the experience of being befriended in people with mental health difficulties (Mitchell, \& Pistrang, 2011), patient views of health practitioner responsiveness to the personal meaning of their chronic pain (Ahlsen, Mengshoel, \& Solbrække, 2012; Angel et al., 2012; Kenny, 2004), the views of residents in a homelessness shelter regarding what consitutes a "therapeutic conversation" (Walsh et al., 2010), and women's views of “listening visits" by community nurses (Turner et al., 2010). Overall, this kind of research into clients' experiences of the counselling skills of their practitioner-helpers, represents a valuable source of insight into the kind of skills and attitudes that make a positive difference. These studies have consistently found that even clients who were vulnerable or limited by communication difficulties have been able to reflect constructively on the emotional support that they have received. For instance, in a study by Gilrane-McGarry and Taggart (2007), that explored the experiences of people with intellectual difficulties who had suffered bereavement, participants were able to differentiate between helpful and unhelpful practices, and to comment on the absence of support from some workers.

In addition to research that has directly asked recipients of embedded counselling to describe their experiences, there have also been some studies that have examined the views of third party participants, such as family members of those who have been recipients of care (see, for example, Lindgren et al., 2010; Neander \& Skott, 2006). A significant theme within some studies of service user experience of embedded counselling has been anger in relation 
to neglectful, disrespectful or abusive responses of practitioners (McLean \& Flynn, 2013; O'Brien et al., 2011). For example, in one Swedish study, parents of young people receiving mental health treatment described themselves as being blamed and emotionally "held to ransom" by care workers (Lindgren et al., 2010). In contrast, qualitative interviews carried out by Neander and Skott (2006) identified exceptional examples of life-changing care and support provided by practitioners of embedded counselling, including instances in which long-standing negative patterns of child behaviour, such as disruptive behaviour in nursery school, were wholly resolved. The findings of these studies demonstrate that it has been possible to identify and analyse a wide range of different responses to embedded counselling, on the part of recipients. However, there remains a great deal that is not well understood about the conditions under which positive or negative experiences of embedded counselling are constructed.

The qualities of helpful and unhelpful embedded counselling conversations

An important area of inquiry within research on embedded counselling has focused on investigating the characteristics that differentiate between helpful and unhelpful counselling conversations. Research into embedded counselling training, the effectiveness of embedded counselling, and the experiences of recipients, has found meaningful and practically relevant differences between "counselling" talk, and routine conversations that take place between nurses, social workers and other practitioners, and their clients. It would appear that the capacity to make subtle, but significant shifts in conversational style, represents a central, and trainable aspect of competence in embedded counselling. 
There have been several studies that have analysed recordings of counselling skills/embedded counselling interactions between practitioners and clients, using the technique of conversation analysis (Drew, Chatwin, \& Collins 2001). A classic, and elegantly simple, study within this tradition was carried out by Heritage et al. (2007), who found that when physicians used the term "some," rather than "any," in statements such as "are there any/some other issues that concern you?", patients were more likely to disclose previously unreported personal worries. In a further example of this type of research, Pillnick (2002) analysed conversations between genetic counsellors and their clients, and was able to identify a set of conversational strategies used by counsellors to deal with challenging moments in sessions: setting the agenda, knowing what is relevant for an individual client, managing different activities, and managing the different perspectives of family members. Other studies have reported similar findings in different samples of practitioners and service users (Frankel; 1984; Gallacher et al., (2001; Heintze et al., 2010; Karhila et al., 2003; Kettunen et al., 2003; Wynn, 2005). Research by Evans et al. (2011) and Paterson et al. (2012) analysed the counselling dimension within acupuncture consultations by coding transcripts of treatment sessions, and found that, in this setting, counselling conversations took the form of intermittent episodes during which the practitioner encouraged the patient to engage in "selfcare talk." These studies have the potential to inform training and practice, by sensitising practitioners to the range of conversational strategies that can be used in embedded counselling.

The organisational context of embedded counselling

Role specifications, and organisational structure and culture, can make a huge difference to the type of counselling relationships that can be developed in healthcare, educational and 
social work settings (McLeod \& McLeod, 2011). For example, the extent to which practitioners are expected to control the behaviour of their clients, inevitably presents a barrier to the establishment of empathic responding. The amount of time that workers are allowed to spend with service users, and the degree of privacy that is available for personal conversations, represent further significant organisational constraints. The studies reported in this paper consist of analyses of situated forms of practice, and therefore include some information about the organisational context within which counselling has taken place. However, there is an absence of research that explicitly foregrounds organisational factors. The potential importance of this aspect of embedded counselling is highlighted in a study by Stein, Frankel and Krupat (2005), into the development of strategies that were adopted within Kaiser Permanente, one of the biggest health providers in the U.S.A., to ensure that physicians engaged empathically, effectively, and in a culture-sensitive manner with the emotional and clinical needs of patients. It was found that these skills and qualities ran counter to prevailing organisational norms and culture, which favoured an instrumental, medical-model way of interacting with patients, and could only be maintained in physicians through the implementation of a wide range of incentives and motivational procedures. Additional evidence of the impact of organisational culture on the provision of emotional support can be found in research by Allan $(2001,2007)$ into the lack of responsiveness to patient distress within an infertility clinic.

Beyond the general topic of organisational culture, one specific contextual factor that has been examined has been the role of front-line practitioners in referring service users to specialist mental health and counselling services (Mannon \& Crawford, 1996; van den Brink et al., 2012). For example, van den Brink et al.,(2012) found that police offers in the 
Netherlands were typically the first practitioners on the scene in situations in which an individual was experiencing a severe mental health crisis, and that the quality of the police response, as a facilitator and gatekeeper in relation to access to specialist services, made a difference to the long-term well-being of the patient and his or her willingness to engage with treatment. However, no research appears to have been published on key contextual issues such as the adequacy of supervision and consultative support for practitioners involved in embedded counselling roles.

\section{Discussion}

It is clear that much valuable work has been done in investigating different aspects of the use of counselling skills by human services practitioners. Taking this body of literature as a whole, it is possible to identify a number of emerging themes and issues. One of the most salient findings is that the willingness of practitioners to engage in counselling-type conversations is highly appreciated by service users, and the absence of such willingness has a negative impact on care. However, the evidence base around the outcomes of embedded counselling is somewhat fragmented. There is a lack of standardised measures or methodologies that would allow outcomes to be compared in different settings, or across different client groups, and allow evaluation of the effects of different counselling models. The absence of follow-up studies is regrettable in the light of the assumption that counselling interventions by front-line practitioners might have a preventative function, by dealing with emotional issues before they develop into symptoms, and forestalling later use of specialist counselling and psychotherapy services. 
Further key themes that have been explored in the research literature, concern the kind, and amount, of training that is necessary for practitioners to be confident and competent in responding to the counselling needs of service users, and the ways in which practitioners respond to empathic opportunities that arise within routine consultations, associated with the expression of emotion.

There have been several studies where service users have been interviewed, where participants report that what has made a difference to them is a relationship with someone who responds to them in an empathic and caring manner. However, authors of these studies have made few links between these findings and the substantial literature within the field of psychotherapy research around the significance of the therapeutic alliance, or the central therapeutic role of the processing and self-regulation of emotions.

A final theme within research on embedded counselling,, relates to the lack of research into the contextual and organisational factors that either support or undermine the delivery of embedded counselling. In recent years there has been a great deal of attention within mainstream counselling and psychotherapy to issues such as supervision, boundaries, and practitioner well-ness. These topics have been somewhat neglected within research on embedded counselling.

The aim of this paper has been to underline the relevance for counselling psychology practitioners of research into embedded counselling. Qualitative studies of service user experiences of embedded counselling provide powerful insights into the type of care that clients may have encountered before entering therapy, or are receiving concurrently with their therapy. Studies of empathic opportunities, and the ways that nurses and physicians 
respond (or do not respond) to expressions of emotion in patients, have generated ideas that are applicable to therapy training and practice. For instance, it could be helpful for trainee counselling psychologists to reflect on their interactions with clients in terms of the categories of emotional responsiveness developed by Adams et al. (2012). There are also fruitful connections to be made between what happens in embedded counselling conversations, and the skills and competencies used by counsellors informed by a social justice perspective (Chung \& Bernak, 2012), which has become increasingly salient within counselling psychology in recent years. For example, the application of social justice principles within the influential Reaching Out About Depression (ROAD) project (Goodman et al. 2009; Weintraub and Goodman 2010) involves counselling psychologists engaging with clients around a range of lifestyle change tasks. This form of practice is similar, in terms of combining therapeutic and practical tasks, to the embedded counselling role of a community nurse, social worker, or priest.

The domain of research into embedded counselling offers exciting opportunities for students, practitioners and academic faculty to carry out research that will further our understanding of the ways in which informal situated counselling can be most effectively delivered in different settings (Barker \& Pistrang, 2002). There are many possibilities for counselling psychology researchers to play a vital role in this endeavour, by initiating and supervising research, and by adapting research tools and strategies that already exist within the counselling psychology and psychotherapy research community. The studies cited in the present paper have been published in journals within a wide array of professional disciplines, such as nursing, medicine, social work, teaching and pastoral care. The concepts and research traditions of counselling psychology, and the capacity of counselling psychologists to draw 
on theory and research from health psychology and occupational psychology, represent a framework through which these interdisciplinary perspectives can be integrated.

\section{References}

Abildsnes, E., Walseth, L.T., Flottorp, S.A., \& Stensland, P.S. (2012). Power and powerlessness: GPs' narratives about lifestyle counselling. British Journal of General Practice, 62(596), 160-166.

Adams, K., Cimino, J.E.W., Arnold, R.M., \& Anderson, W.G. (2012). Why should I talk about emotion? Communication patterns associated with physician discussion of patient expressions of negative emotion in hospital admission encounters. Patient Education and Counseling, 89, 44-50.

Adams-Skinner, J., Exner, T., Pili, C., Wallace, B., Hoffman, S., \& Leu, C.S. (2009). The development and validation of a tool to assess nurse performance in dual protection counselling. Patient Education and Counseling, 76, 265-271.

Ahlsen, B., Mengshoel, A.M., \& Solbrække, K.N. (2012). Shelter from the storm; men with chronic pain and narratives from the rehabilitation clinic. Patient Education and Counseling, 89, 316-332.

Allan, H. (2001). A 'good enough' nurse: supporting patients in a fertility unit. Nursing Inquiry, 8, 51-60.

Allan, H. (2007). Experiences of infertility: liminality and the role of the fertility clinic. Nursing Inquiry, 14, 132-139. 
Anderson, S., \& Brownlie, J. (2011). Build it and they will come? Understanding public views of 'emotions talk' and the talking therapies. British Journal of Guidance and Counselling, 39, 53-66.

Angel, S., Jensen, L.D., Gonge, B.K., Maribo, T., Schiottz-Christensen, \& Buus, N. (2012) Patients' interpretations of a counselling intervention for low back pain: A narrative analysis. International Journal of Nursing Studies, 49, 784-792.

Axline, V.M., \& Rogers, C.R. (1945). A teacher-therapist deals with a handicapped child. Journal of Abnormal and Social Psychology, 40, 119-142.

Barker, C.. Pistrang, N., Shapiro, D.A., \& Shaw, I. (1990). Coping and help-seeking in the UK adult population. British Journal of Clinical Psychology, 29, 271-285

Barker, C., \& Pistrang, N. (2002). Psychotherapy and social support: integrating research on psychological helping. Clinical Psychology Review, 22, 361-379.

Bender, A., Peter, E., Wynn, F., Andrews, G., \& Pringle, D. (2011). Welcome intrusions: An interpretive phenomenological study of TB nurses' relational work. International Journal of Nursing Studies, 48, 1409-1419.

Blanch-Hartigan, D. (2011). Measuring providers' verbal and nonverbal emotion recognition ability: Reliability and validity of the Patient Emotion Cue Test (PECT). Patient Education and Counseling, 82, 370-376.

Blanch-Hartigan, D. (2012). An effective training to increase accurate recognition of patient emotion cues. Patient Education and Counseling, 89, 274-280. 
Bonvicini, K.A., Perlin, M.J., Bylund, C.L., Carroll, G., Rouse, R.A., \& Goldstein, M.G. (2009). Impact of communication training on physician expression of empathy. Patient Education and Counseling, 75, 3-10.

Boyle, J., Kernohan, G.W., \& Rush, W. (2009). 'When you are tired or terrified your voice slips back into its old first place': the role of feelings in community mental health practice with forensic patients. Journal of Social Work Practice, 23, 291-313.

Branch, W.T, \& Malik, T.K. (1993). Using 'windows of opportunities' in brief interviews to understand patients' concerns. Journal of the American Medical Association, 269, 16671668.

Bylund, C.L., \& Makoul, G. (2002). Empathic communication and gender in the physicianpatient encounter. Patient Education and Counseling, 48, 207-216.

Bylund, C.L, \& Makoul, G. (2005). Examining empathy in medical encounters: an observational study using the empathic communication coding system. Health Communication, 18, 123-140.

Childers, J.W., Bost, J.E., Kraemer, K.L., \& Cluss, P.A. (2012). Giving residents tools to talk about behavior change: A motivational interviewing curriculum description and evaluation. Patient Education and Counseling, 89, 281-287.

Chung, R.C., \& Bernak, F.P. (2012). Social Justice Counselling. The Next Steps Beyond Multiculturalism. Thousand Oaks, CA: Sage. 
Degner, J., Henriksen, A., \& Oscarsson, L. (2010). Investing in a formal relationship: support persons' view of treatment involvement regarding young persons in residential care. Qualitative Social Work, 9, 321-342.

Dowling, S., Hubert, J., White, S., \& Hollins, S. (2006). Bereaved adults with intellectual disabilities: a combined randomized controlled trial and qualitative study of two community-based interventions. Journal of Intellectual Disability Research, 50, 277-287.

Drew, P., Chatwin, J., \& Collins, S. (2001). Conversation analysis: a method for research into interactions between patients and healthcare professionals. Health Expectations: An International Journal of Public Participation in Health Care and Health Policy, 4, 5870.

Easton, S., \& van Laar, D. (1995). Experiences of lecturers helping distressed students in higher education. British Journal of Guidance and Counselling, 23, 173-178.

Eide, H., Frankel, R., Haaversen, C, Vaupel, K., Graugard, P., \& Finset, A. (2004). Listening for feelings: identifying and coding empathic and potential empathic opportunities in medical dialogues. Patient Education and Counseling, 54, 291-297.

Engebretson, J. (2000). Caring presence: a case study. International Journal for Human Caring, 4, 211-223. 
Evans, M., Paterson, C., Wye, L., Chapman, R., Robinson, J., Norton, R., \& Bertschinger, R. (2011). Lifestyle and self-care advice within traditional acupuncture consultations: A qualitative observational study nested in a co-operative inquiry. Journal of Alternative and Complementary Medicine, 17, 519-529.

Eyrich-Garg, K.M. (2008). Strategies for engaging adolescent girls at an emergency shelter in a therapeutic relationship: recommendations from the girls themselves. Journal of Social Work Practice, 22, 375-388.

Flesaker, K., \& Larsen, D. (2012). To offer hope you must have hope: accounts of hope for reintegration counsellors working with women on parole and probation. Qualitative Social Work, 11, 61-79.

Frankel, R.M. (1984). From sentence to sequence: understanding the medical encounter through micro-interactional analysis. Discourse Process, 7, 135-170.

Gallacher, T.J., Hartung, P.J., \& Gregory jr., S.W. (2001). Assessment of a measure of relational communication for doctor-patient interaction. Patient Education and Counseling, 45, 211-218.

Gao, L., Chan, S.W., \& Sun, K. (2012). Effects of an interpersonal-psychotherapy-oriented childbirth education programme for Chinese first-time childbearing women at 3-month follow up: Randomised controlled trial. International Journal of Nursing Studies, 49, $274-281$. 
Gilrane-McGarry, U., \& Taggart, L. (2007). An exploration of the support received by people with intellectual disabilities who have been bereaved. Journal of Research in Nursing, $12,129-144$.

Glowa, P.T., Frasier, P.Y., \& Newton, W.P. (2002). Increasing physician comfort level in screening and counseling patients for intimate partner violence: hands-on practice. Patient Education and Counseling, 46, 213-220.

Goodman, L.A., Glenn, C., Bohlig, A., Banyard, V., \& Borges, A. (2009). Feminist Relational Advocacy: processes and outcomes from the perspective of low-income women with depression. Counseling Psychologist, 37, 848-876.

Grayson, A., Miller, H., \& Clarke, D. (1998). Identifying barriers to help-seeking: a qualitative analysis of students' preparedness to seek help from tutors. British Journal of Guidance and Counselling, 26, 237-254.

Greenhalgh, T., Robert, G., Macfarlane, F., Bate, P., Kyriakidou, O., \& Peacock, R. (2005). Storylines of research in diffusion of innovation: a meta-narrative approach to systematic review. Social Science and Medicine, 61, 417-430.

Heintze, C., Metz, U., Hahn, D., Niewohner, J., Schwantes, U., Wiesner, J., \& Braun, V. (2010). Counseling overweight in primary care: An analysis of patient-physician encounters. Patient Education and Counseling, 80, 71-75.

Henderson, J.T., Raine, T., Schalet, A., Blum, M. \&. Harper, C.C. (2011). 'I wouldn't be this firm if I didn't care": Preventive clinical counseling for reproductive health. Patient Education and Counseling, 82, 254-259. 
Heritage, J., Robinson, J.D., Elliott, M.N., Beckett, M., \& Wilkes, M. (2007). Reducing patients' unmet concerns in primary care: the difference one word can make. Journal of General Internal Medicine, 22, 1429-1433.

Henshaw,E.J., Flynn, H.A., Himle, J.A., O’Mahen, H.A., Forman,J., \& Fedock, G. (2011). Patient preferences for clinician interactional style in treatment of perinatal depression. Qualitative Health Research, 21, 936-951.

Hill, C.E. (ed.) (2001) Helping Skills: the Empirical Foundation. Washington, DC: American Psychological Association.

Hill, C.E., \& Kellems, I.S. (2002). Development and use of the Helping Skills Measure to assess client perceptions of the effects of training and of helping skills in session evaluation. Journal of Counseling Psychology, 49, 264-272.

Hill, C.E., \& Lent, R.W. (2006). A narrative and meta-analytic review of helping skills training: time to revive a dormant area of inquiry. Psychotherapy: Theory, Research, Practice, Training, 43, 154-172.

Hochschild, A. (1983). The Managed Heart: the Commercialization of Human Feeling. Berkeley, CA: University of California Press.

Holden, J.M., Sagovsky, R., \& Cox, J.L. (1989). Counselling in a general practice setting: controlled study of health visitor intervention in treatment of postnatal depression. British Medical Journal, 298(6668), 223-226. 
Høigaarda, R., \& Mathisen, P. (2008). Informal situated counselling in a school context. Counselling Psychology Quarterly, 21, 293-299.

Jansen, J., van Weert, J.C.M., de Groot, J., van Dulmen, S., Heeren, J., \& Bensing, J.M. (2010). Emotional and informational patient cues: The impact of nurses' responses on recall. Patient Education and Counseling, 79, 218-224.

Janssen, A.L., \& MacLeod, R.D. (2010). What can people approaching death teach us about how to care? Patient Education and Counseling, 81, 251-256.

Kane, M.N. (2010). Predictors of university students' willingness in the USA to use clergy as sources of skilled help. Mental Health, Religion and Culture, 13, 309-325.

Karhila, P., Kettunen, T., Poskiparta, M., \& Liinatainen, L. (2003). Negotiation in Type 2 Diabetes counseling: from problem recognition to mutual acceptance during lifestyle counselling. Qualitative Health Research, 13, 1205-1224.

Kennifer, S.L., Alexander, S.C., Pollak, K.I., Jeffreys, A.S., Olsen, M.K., Rodriguez, K.L., Arnold, R.M., \& Tulsky, J.A. (2009). Negative emotions in cancer care: Do oncologists' responses depend on severity and type of emotion? Patient Education and Counseling, 76, 51-56.

Kenny, D.T (2004). Constructions of chronic pain in doctor-patient relationships: bridging the communication chasm. Patient Education and Counseling, 52, 297-305. 
Kettunen, T., Poskiparta, M., \& Karhila, P. (2003). Speech practices that facilitate patient participation in health counselling - a way to empowerment? Health Education Journal, 62, 326-340.

Kim, S.S., Kaplowitz, S., \& Johnston, M.V. (2004). The effects of physician empathy on patient satisfaction and compliance. Evaluation and the Health Professions, 27, 237251.

Kind, T., Everett, V.R., \& Ottolini, M. (2009). Learning to connect: Students' reflections on doctor-patient interactions. Patient Education and Counseling, 75, 149-154.

Kinman, G., McFall, O., \& Rodriguez, J. (2011). The cost of caring? Emotional labour, wellbeing and the clergy. Pastoral Psychology, 60, 671-680.

Kuntze, J., van der Molen, H.T., \& Born, M.P. (2007). Progress in mastery of counseling communication skills: development and evaluation of a new instrument for the assessment of counselling communication skills. European Psychologist, 12, 301-313.

Larson E.B., \& Yao. X. (2005). Clinical empathy as emotional labor in the patient-physician relationship. Journal of the American Medical Association, 293, 1100-1106.

Leavey, G., Loewenthal, K., and King, M. (2007). Challenges to sanctuary: The clergy as a resource for mental health care in the community. Social Science and Medicine, 65, 548-559.

Lent, R.W., Hill, C.E., \& Hoffman, M.A. (2003). Development and validation of the counselor activity self-efficacy scale. Journal of Counseling Psychology, 50, 97-108. 
Levy-Storms, L. (2008). Therapeutic communication training in long-term care institutions: Recommendations for future research. Patient Education and Counseling, 73, 8-21.

Linden, J., Stone, S., \& Shertzer, B. (1965). Development and evaluation of an inventory for rating counseling. Personnel and Guidance Journal, 44, 267-276.

Lindgren, B.-M., Sture, A., \& Graneheim, U.H. (2010). Held to ransom: Parents of selfharming adults describe their lived experience of professional care and caregivers. International Journal on Qualitative Studies of Health and Well-being, 5, 1-10.

Lount, M. \& Hargie, O. (1997). The priest as counsellor: an investigation of critical incidents in the pastoral work of Catholic priests. Counselling Psychology Quarterly, 10, 259271.

Maiter, S., Palmer, S., \& Manji, S. (2006). Strengthening social worker-client relationships in child protective services: addressing power imbalances and 'ruptured' relationships. Qualitative Social Work, 5, 161-186.

Mannon, D., \& Crawford, R. (1996). Clergy confidence to counsel and their willingness to refer to mental health professionals. Family Therapy, 23, 213-231.

McLean, A., \& Flynn, C. (2013) 'It's not just a pap-smear': Women speak of their experiences of hospital treatment after miscarriage Qualitative Social Work

McLeod, John, \& McLeod, Julia (2011). Counselling skills. A practical guide for counsellors and helping professionals. $2^{\text {nd }}$ edn. Maidenhead: Open University Press.

McLeod, J., \& Rodgers, B. (2008). Evaluation of brief counselling skills training for community workers. Counselling in Scotland, 10(2), 8-16. 
Mercer, S.W., Maxwell, M., Heaney, D., \& Watt, G.C.M. (2004). The consultation and relational empathy (CARE) measure: development and preliminary validation and reliability of an empathy-based consultation process measure. Family Practice, 21, 699705.

Mercer, S.W., McConnachie, A., Maxwell, M., Heaney, D., \& Watt, G.C.M. (2005). Relevance and practical use of the Consultation and Relational Empathy (CARE) measure in general practice. Family Practice, 22, 328-334.

Mitchell, G., \& Pistrang, N. (2011). Befriending for mental health problems: Processes of helping. Psychology and Psychotherapy: Theory, Research and Practice, 84, 151-169

Morrell, C.J., Slade, P., Warner, R., Paley, G., Dixon, S., Walters, S.J., Brugha, T., Barkham, M., Parry, G.J., \& Nicholl, J. (2009). Clinical effectiveness of health visitor training in psychologically informed approaches for depression in postnatal women: pragmatic cluster randomised trial in primary care. British Medical Journal, 338, 3045.

Neander, K., \& Skott, C. (2006). Important meetings with important persons: narratives from families facing adversity and their key figures. Qualitative Social Work, 5, 295-311.

Nerdrum, P., \& Rønnestad, M.H. (2002). The trainees' perspective: a qualitative study of learning empathic communication in Norway. The Counseling Psychologist, 30, 609629.

O’Brien, R., Rose, P., Campbell, C., \& Weller, D. (2011) “I wish I'd told them": A qualitative study examining the unmet psychosexual needs of prostate cancer patients during follow-up after treatment. Patient Education and Counseling, 84, 200-207. 
O'Kane, S. \& Millar, R. (2001). An investigation into the counselling-type work of Roman Catholic priests: a survey of one diocese in Northern Ireland. British Journal of Guidance and Counselling, 29, 323-335.

O'Kane, S., \& Millar, R. (2002). A qualitative study of pastoral counselling of Catholic priests in Northern Ireland. British Journal of Guidance and Counselling, 30, 189-206.

Page, K.S., \& Jacobs, S.C. (2011). Surviving the shift: Rural police stress and counseling services. Psychological Services, 8, 12-22.

Paterson, C., Evans, M., Bertschinger, R., Chapman, R., Norton, R., \& Robinson, J. (2011). Communication about self-care in traditional acupuncture consultations: The coconstruction of individualised support and advice. Patient Education and Counseling, $89,467-475$.

Pilnick, A. (2002). 'There are no rights and wrongs in these situations': identifying interactional difficulties in genetic counselling. Sociology of Health and Illness, 24, 6688.

Pilnick, A. (2003). 'Patient counselling' by pharmacists: four approaches to the delivery of counselling sequences and their interactional reception. Social Science and Medicine, $56,835-849$.

Porr, C., Drummond, J., \& Olson, K. (2012). Establishing therapeutic relationships with vulnerable and potentially stigmatized clients. Qualitative Health Research, 22, 384396. 
Quirk, M., Mazor, K., Haley, H., Philbin, M., Fischer, M., Sullivan, K., \& Hatem, D. (2008). How patients perceive a doctor's caring attitude. Patient Education and Counseling, 72, 359-366.

Sheldon, L.S., Ellington, L., Barrett, R., Dudley, W.N., Clayton, M.F., \& Rinaldi, K. (2009). Nurse responsiveness to cancer patient expressions of emotion. Patient Education and Counseling, 76, 63-70.

Stahl, J.V., \& Hill, C.E. (2008). A comparison of four methods for assessing natural helping ability. Journal of Community Psychology, 36, 289-298.

Stein, T., Frankel, R.M., \& Krupat, E. (2005). Enhancing clinician communication skills in a large healthcare organization: a longtitudinal case study. Patient Education and Counseling, 58, 4-12..

Stone, A.L., Tai-Selae, M., Stults, C.D., Luiz, J.M., \& Frankel, R.M. (2012). Three types of ambiguity in coding empathic interactions in primary care visits: Implications for research and practice. Patient Education and Counseling, 89, 63-68.

Tatar, M. (2009). Teachers turning for help to school counsellors and colleagues: Toward a mapping of relevant predictors. British Journal of Guidance \& Counselling, 37, 107127.

Turner, K.M., Chew-Graham, C., Folkes, L., \& Sharp, D. (2010). Women's experiences of health visitor delivered listening visits as a treatment for postnatal depression: A qualitative study. Patient Education and Counseling, 78, 234-39. 
Ungar, M., Barter, K., McConnell, S.M., Tutty, L.M., \& Fairholm, J. (2009). Patterns of abuse disclosure among youth. Qualitative Social Work, 8, 341-356.

van den Brink, R.H.S., Broer, J., Tholen, A.J., Winthorst, W.H., Visser, E., \& Wiersma, D. (2012) Role of the police in linking individuals experiencing mental health crises with mental health services. BMC Psychiatry, 12, 171.

Walsh, C.A., Rutherford, G.E., Sarafincian, K.N., \& Sellmer, S.E.R. (2010). Making meaning together: An exploratory study of therapeutic conversation between helping professionals and homeless shelter residents. The Qualitative Report, 15, 932-947.

Weintraub, S.R., \& Goodman, L.A. (2010). Working with and for: student advocates' experience of relationship-centered advocacy with low-income women. American Journal of Orthopsychiatry, 80, 46-60.

Wynn, R., \& Wynn, M. (2006). Empathy as an interactionally achieved phenomenon in psychotherapy. Characteristics of some conversational resources. Journal of Pragmatics, 38, 1385-1397. 